\title{
The Positive Rate of Pulmonary Embolism by CT Pulmonary Angiography Is High in an Emergency Department, Even in Low-Risk or Young Patients
}

\author{
Nizam Al-Zaher Francesco Vitali Markus F. Neurath Ruediger S. Goertz \\ Department of Internal Medicine 1, Friedrich-Alexander-University Erlangen-Nurnberg, Erlangen, Germany
}

\section{Highlights of the Study}

- CT pulmonary angiography often proves a suspected pulmonary embolism in emergency patients.

- A pulmonary embolism is quite common even in low-risk Wells score or in young patients $<40$ years.

- Differential diagnosis of chest pain or dyspnea should include pulmonary embolism.

\section{Keywords}

Pulmonary embolisms · CT pulmonary angiography ·

Dyspnea $\cdot$ Chest pain · Emergency

\begin{abstract}
Objective: The clinical presentation of pulmonary embolism (PE) can be various and misleading. We analyzed patients with suspicion of $\mathrm{PE}$ and subsequently performed computed tomography pulmonary angiography (CTPA) in an emergency department of Internal Medicine, focusing on patient groups in which PE might be underestimated in the emergency setting, such as young patients and patients with low clinical probability. Material and Methods: In 2016 and 2017, all patients receiving a CTPA for investigation of PE were retrospectively evaluated for clinical parameters (age, symptoms, and vital parameters) and D-dimers. The Wells score was calculated. Results: CTPA was performed in 323 patients (158 female and 165 male; mean age 62 years). The
\end{abstract}

leading symptoms for admission were dyspnea or chest pain; $62 \%$ showed intermediate or high risk for $\mathrm{PE}$, calculated by applying the Wells score. In 123 (38\%) of all patients, a PE was proved and pathologic age-adjusted D-dimers were found in $97.6 \%$. Thirty of 121 (25\%) patients with low risk according to Wells score had a PE. Deep vein thrombosis was verified in $67 / 123(55 \%)$ patients; $43 \%(15 / 35)$ of all suspicions for PE in patients $<40$ years were positive with $4 / 15$ $(26 \%)$, showing a central PE. Younger patients ( $<40$ years) with PE presented more often with tachycardia or tachypnea and chest pain or dyspnea than elderly patients with PE. Conclusion: CTPA frequently proves a PE in patients with suspicion of PE in an emergency department of Internal Medicine. If PE is suspected and CTPA performed accordingly, the presence of PE is quite common even in low-risk patient groups (Wells score) or in young patients $<40$ years with chest pain or dyspnea.

(c) 2020 The Author(s)

Published by S. Karger AG, Basel karger@karger.com www.karger.com/mpp

Karger ${ }^{\prime \prime} \div$

GOPEN ACCESS
(C) 2020 The Author(s)

Published by S. Karger AG, Basel

This is an Open Access article licensed under the Creative Commons Attribution-NonCommercial-4.0 International License (CC BY-NC) (http://www.karger.com/Services/OpenAccessLicense), applicable to the online version of the article only. Usage and distribution for commercial purposes requires written permission.
Ruediger S. Goertz

Department of Internal Medicine 1, Friedrich-Alexander-University Erlangen-Nurnberg Ulmenweg 18

DE-91054 Erlangen (Germany)

ruediger.goertz@fau.de 


\section{Introduction}

Pulmonary embolism (PE) is still one of the main causes of death in hospitalized patients [1]. Studies have shown that PE can be identified in $>26 \%$ of autopsies, with $9 \%$ relating patient death to fatal PE. Being a potentially life-threatening condition, unrecognized PE may have fatal consequences [2]. In the past, mortality of missed PE has been estimated to be in a range from 5 up to $30 \%$. Therefore, a fast and precise diagnostic workup is indispensable. However, the unspecific signs and symptoms associated with PE make a rapid diagnostic evaluation challenging for the physician in an emergency department. Various guidelines recommend a graduated clinical approach using algorithms such as Wells score and revised Geneva score, categorizing patients into low, intermediate, and high clinical probability [3-5]. The reference method for diagnosing or excluding PE is computed tomography pulmonary angiography (CTPA). CTPA represents the most sensitive and precise diagnostic test especially in high-probability cases [6]. Determination of D-dimer levels is recommended in case of low and intermediate clinical probability [5]. Carrying a relatively low specificity for $\mathrm{PE}$, the approach of using positive D-dimer as a standard prerequisite for performing CTPA would lead to a higher number of potential consequences such as contrast nephropathy, allergic reactions to contrast media, radiation exposure, and higher financial burden for health care facilities [7]. In general, a combined strategy of clinical probability and D-dimer testing represents an opportunity for fast clarification. Pathologic values make a CTPA mandatory. This challenging situation in emergency departments has led to various clinical retrospective studies, evaluating the probability of $\mathrm{PE}$ in the general patient population $[8,9]$. However, little is known about $\mathrm{PE}$ in young patient groups in which this diagnosis is usually not expected. Based on this knowledge, we evaluated the role of CTPA in diagnosing PE in an emergency department, with an emphasis on analysis in different age-groups.

\section{Material and Methods}

\section{Patients}

This retrospective analysis included data from medical records of our emergency department of Internal Medicine (University Hospital Erlangen, Friedrich-Alexander-University ErlangenNurnberg, Bavaria, Germany). The study complied with the ethical principles of the World Medical Association Declaration of Helsinki and was approved by the local Ethics Committee. About 10,500 patients per year are admitted to the emergency depart- ment. All patients were included who underwent CTPA for suspicion of PE between January 1, 2016, and December 31, 2017. CTPA - available $24 \mathrm{~h}$ - was ordered by the physician based on the overall clinical evaluation in the emergency department or when clinical suspicion of PE was high. Alternatively, CTPA was ordered in unclear patient presentation with elevated D-dimers.

\section{Clinical Features}

Data were obtained from medical records filled in by nurses and physicians in the emergency department on admission as well as from physician letters and other medical results documented in Soarian Health Archives (Soarian Clinicals, Medical Data Software of the medical faculty, Siemens, Erlangen). Apart from basic data (sex, age, date of CTPA, and reason for admission), records were reviewed for vital signs, blood gas analysis, symptoms and reasons for admission, clinical scores (Wells and revised Geneva scores), laboratory values, as well as results from electrocardiogram (ECG), echocardiography, deep vein ultrasound (within $24 \mathrm{~h}$ after admission), and CTPA. Vital signs, reasons for admission and presence of unilateral lower leg edema, and/or pain were evaluated (specific items shown in Table 1). ECG results were evaluated for signs of S1Q3 and/or right bundle branch block. The Wells score was taken from emergency department records or retrospectively calculated, along with the (revised) Geneva score. Core diagnostic parameters (patient age, D-dimer level, presence of dyspnea, chest pain, unilateral leg edema and/or leg pain) were analyzed according to the presence or absence of PE. D-dimer cutoff was $500 \mathrm{ng} / \mathrm{mL}$ for patients $<50$ years old. For patients $>50$ years, the age was multiplied by the factor $10 \mu \mathrm{g} / \mathrm{L}$, and the result served as an age-adjusted cutoff value $[3,10,11]$. Sensitivity of D-dimer testing (ELISA) for excluding thromboembolism is $\geq 95 \%$ in our laboratory. Troponin I (normal $<0.5 \mathrm{ng} / \mathrm{mL}$ ) and $\mathrm{Cr}$ (normal $<0.95 \mathrm{mg} / \mathrm{dL}$ ) values were analyzed. Hereafter, patients were classified according to Wells criteria for PE in its original version $[12,13]$. Earlier deep vein thrombosis or PE, heart rate $\geq 100 / \mathrm{min}$, surgery, or immobilization during the last 4 weeks represents 1.5 score points each. The presence of hemoptysis and/or active neoplasia represents 1 point each. Three points are given in case of clinical sign of deep vein thrombosis or if an alternative diagnosis is unlikely. Hence, patients were classified into low (0-1 points), intermediate ( $2-6$ points), or high risk ( $\geq 7$ points) for $\mathrm{PE}$. The Geneva score in its simplified version counted 1 point each for the following parameters: earlier deep vein thrombosis or PE, surgery or fracture during the last 3 months, hemoptysis, active neoplasia, unilateral leg pain, pain on deep palpation of lower extremity + unilateral edema, age $>65$ years, and heart rate $75-94 / \mathrm{min}$ 2 points were added if the heart rate was $\geq 95[4,14]$.

\section{CT Tomography Pulmonary Angiography}

The CTPA of each patient was performed with either Somatom Definition AS CT or Somatom Force CT (Siemens Medical System, Erlangen, Germany). The scan volume included the entire thorax from lung apex to its base in the craniocaudal direction. The slice thickness was $0.75 \mathrm{~mm}$. Monitoring started $10 \mathrm{~s}$ after administration of contrast media (in most cases Imeron 350, $50 \mathrm{~mL}$ ). Flow rate was at least $3 \mathrm{~mL} / \mathrm{s}$ with Somatom Definition AS CT or at least $4 \mathrm{~mL} / \mathrm{s}$ with Somatom Force CT and flushed with 50-60 $\mathrm{mL} \mathrm{NaCl}$. CTPA interpretation was done by a radiologist highly experienced in diagnosing pulmonary conditions like PE. Results of CTPA were categorized into "PE" or "no PE" as well as the extent of blood vessel occlusion (Table 3) [15]. Extent to peripheral 
Table 1. Overall characteristics of 323 patients with suspicion of PE and performance of CTPA in an emergency department

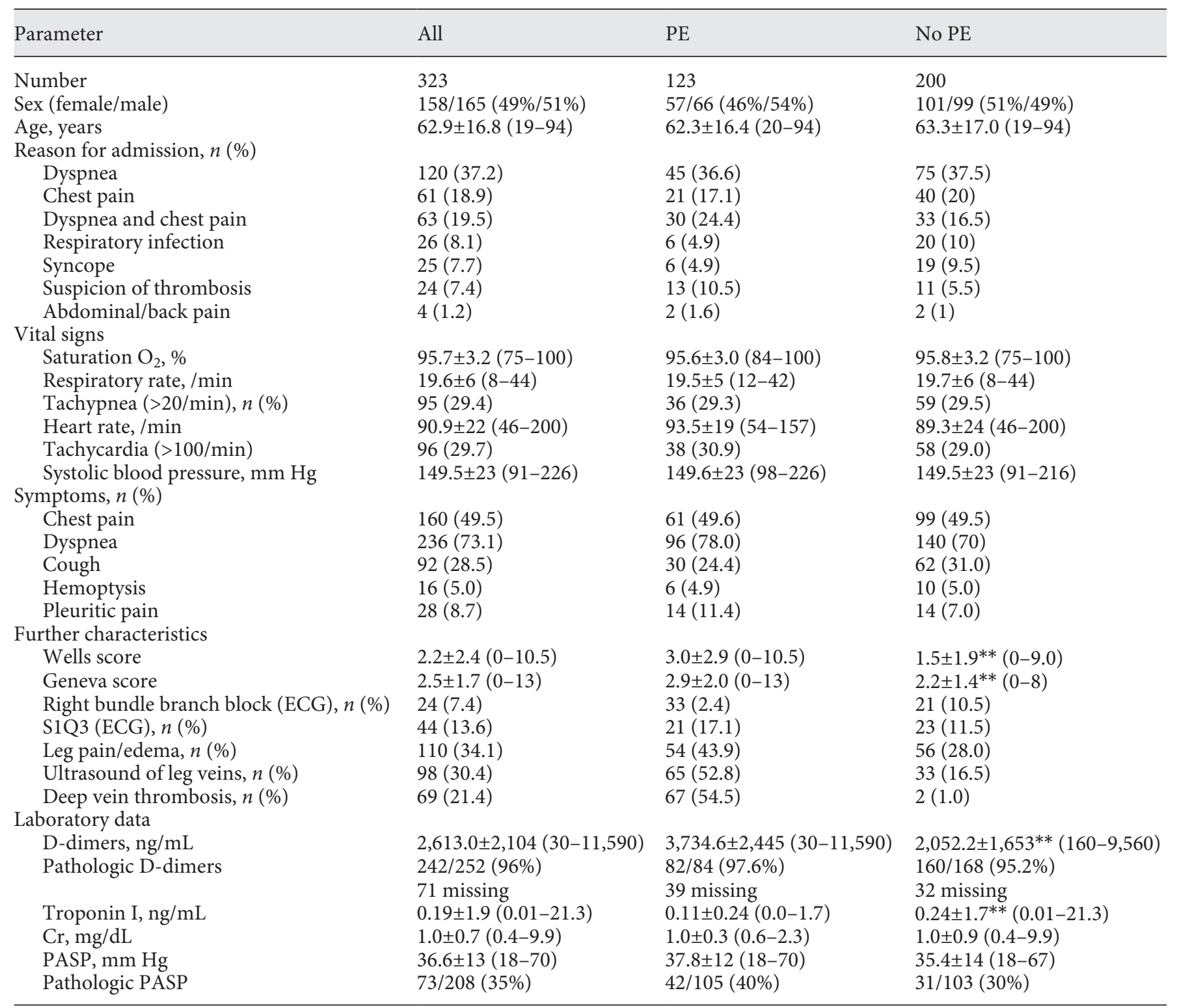

PASP, pulmonary artery systolic pressure; PE, pulmonary embolism; CTPA, computed tomography pulmonary angiography; ECG, electrocardiogram. ${ }^{* *} p<0.001$.

branches was considered a definite PE diagnosis (or positive CTPA), as was PE of the other, higher 3 categories.

\section{Statistical Analysis}

For statistical evaluation of collected data, values were presented as frequency, mean, and standard deviation together with the range or proportion (\%). To compare the means, the $t$ test was used. A statistically significant result was indicated by $p<0.05$. The Statistical Package for the Social Sciences (version 24.0.0.2, IBM Corp., Armonk, NY, USA) supported the explorative data analysis.

\section{Results}

Among the 323 patients (mean age 62 years), 158 were female, and 165 were male. In 123/323 (38\%) patients, PE was detected (Table 1). Dyspnea, chest pain, or both symptoms were found to be the reason for admission in overall $76 \%$ of all patients, presenting the same proportions in patient groups with PE and without. Respiratory infection and syncope were shown in $15.8 \%$ of admis- 
Table 2. Calculated risk by the Wells score, pathologic D-dimers, and presence of $\mathrm{PE}$ according to different age-groups

\begin{tabular}{|c|c|c|c|c|c|c|c|c|c|}
\hline \multirow[t]{3}{*}{ Wells score } & \multirow[t]{3}{*}{$n$} & \multicolumn{4}{|l|}{$\mathrm{PE}$} & \multicolumn{4}{|l|}{ No PE } \\
\hline & & \multicolumn{3}{|l|}{ Age, years } & \multirow[t]{2}{*}{ All PE } & \multirow[t]{2}{*}{ No PE } & \multicolumn{3}{|l|}{ Age, years } \\
\hline & & $<40$ & $40-60$ & $>60$ & & & $<40$ & $40-60$ & $>60$ \\
\hline Low risk & $121(37 \%)$ & $1(7 \%)$ & $11(38 \%)$ & $18(23 \%)$ & $30 / 121(25 \%)$ & $91 / 121(75 \%)$ & $13(65 \%)$ & $24(41 \%)$ & $54(55 \%)$ \\
\hline Pathologic D-dimers & $100 / 106(94 \%)$ & $1 / 1$ & $10 / 10$ & $13 / 14$ & $24 / 25(96 \%)$ & 76/81 (94\%) & $10 / 10$ & $22 / 22$ & $44 / 49$ \\
\hline Intermediate risk & $177(55 \%)$ & $12(80 \%)$ & $12(41 \%)$ & $48(61 \%)$ & $72 / 177(41 \%)$ & $105 / 177(59 \%)$ & $6(30 \%)$ & $35(59 \%)$ & $64(52 \%)$ \\
\hline Pathologic D-dimers & $125 / 129(97 \%)$ & $10 / 11$ & $9 / 9$ & $26 / 26$ & $45 / 46(98 \%)$ & $80 / 83(96 \%)$ & $6 / 6$ & $21 / 22$ & $53 / 55$ \\
\hline High risk & $25(8 \%)$ & $2(13 \%)$ & $6(21 \%)$ & $13(16 \%)$ & $21 / 25(84 \%)$ & $4 / 25(16 \%)$ & $1(5 \%)$ & 0 & $3(3 \%)$ \\
\hline Pathologic D-dimers & $17 / 17(100 \%)$ & $2 / 2$ & $4 / 4$ & $7 / 7$ & $13 / 13(100 \%)$ & $4 / 4(100 \%)$ & $1 / 1$ & 0 & $3 / 3$ \\
\hline \multirow[t]{2}{*}{$n$} & 323 & 15 & 29 & 79 & $123(38 \%)$ & $200(62 \%)$ & 20 & 59 & 121 \\
\hline & & & & & $82 / 84$ & $160 / 168$ & & & \\
\hline
\end{tabular}

PE, pulmonary embolism.

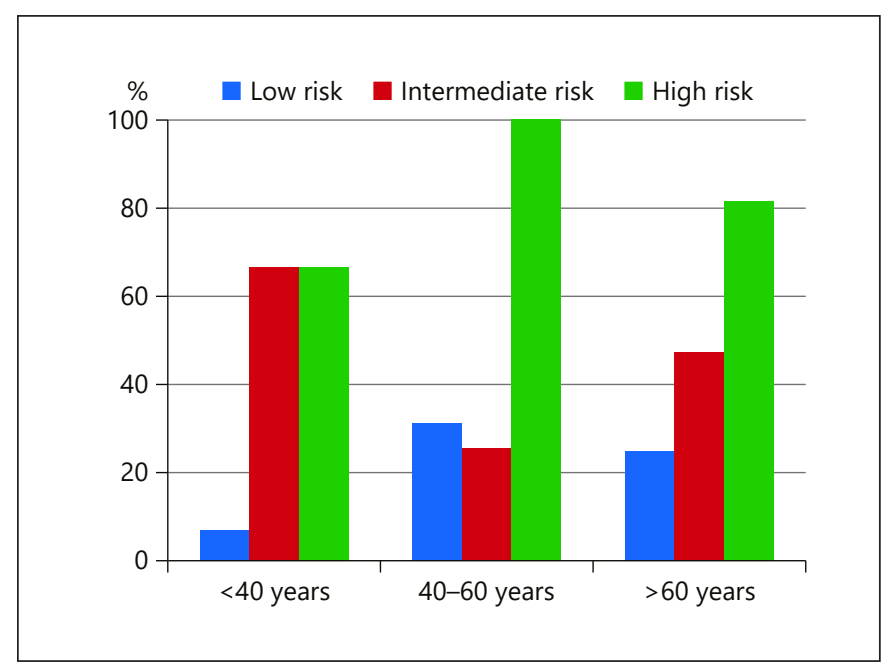

Fig. 1. Positive rate of CTPA in an emergency department according to clinical risk assessment (Wells) and age-groups. CTPA, computed tomography pulmonary angiography.

sions. Tachycardia and tachypnea were present in approximately $30 \%$ in the groups with $\mathrm{PE}$ and without $\mathrm{PE}$, respectively. Leg pain and/or edema were observed in $23 \%$ of cases without PE and in $43.9 \%$ of cases with PE, along with proven deep vein thrombosis in up to $54.5 \%$ cases. A documented Wells score was found in $8 / 323$ $(2.5 \%)$ patients. The following data were missing (or examinations not performed): $71 \mathrm{D}$-dimers, 30 troponin I, $3 \mathrm{Cr}$, and 115 echocardiographies. In patients with $\mathrm{PE}$, the mean Wells score was 3.0, and in patients without PE 1.5.

Overall, the calculated Wells score showed mostly intermediate risk of $\mathrm{PE}$, then low risk, and rarely high risk (Table 2). The presence of proven PE accounted for $84 \%$ of high-risk and $25 \%$ of low-risk patients (Fig. 1). Patients $<40$ years with PE showed low risk according to the Wells score in 1 case. D-dimers were pathologic (age-adjusted) in $98 \%$ of PE patients and $95 \%$ in the absence of PE. In $15 / 121(12 \%)$ patients with a low risk, determination of D-dimer levels was not performed or missing. In the group of $<40$ years, $43 \%$ of all CTPA were positive for PE (Table 2), compared to $33 \%$ in the group $40-60$ years and $39.5 \%$ in the group $>60$ years (with the highest absolute number of proven PE $[n=79]$ ). $60 \%$ of patients $<40$ years had PE within peripheral branches or segmental arteries, whereas the extent to the main pulmonary artery or its branch showed a higher percentage in patients aged $\geq 40$ and $>60$ years (Table 3 ). In our study, the extent of PE did not correlate with patient age $(r=-0.03 ; p>0.05)$. Looking at the characteristics of 123 patients with $\mathrm{PE}$ according to different age-groups (Table 4), 20/29 patients with $\mathrm{PE}$ in the group 40-60 years were male. Tachypnea, tachycardia, and chest pain showed the highest percentage in patients $<40$ years (Table 4 ). Ultrasound of leg veins was performed in $66.6 \%$ of patients $<40$ years with proven PE, the highest percentage of all age-groups. The mean D-dimer was lower in patients $<40$ years with $\mathrm{PE}$ than that in the higher aged groups with PE. In 1 patient $<40$ years with peripheral PE, D-dimers were not pathologic.

\section{Discussion}

Our results show that $38 \%$ of patients who underwent CTPA had the final diagnosis of PE. In particular, in case of chest pain and dyspnea, PE should be part of the differential diagnosis, also in younger patients. A systematic 
Table 3. Extent of PE in CTPA (PE 1-4) according to different age-groups

\begin{tabular}{lcccc}
\hline Age, years & $<40$ & $40-60$ & $>60$ & Total \\
\hline PE & $15 / 35(43 \%)$ & $29 / 88(33 \%)$ & $79 / 200(39.5 \%)$ & $123 / 323(38 \%)$ \\
No PE & $20 / 35(57 \%)$ & $59 / 88(67 \%)$ & $121 / 200(60 \%)$ & $200 / 323(62 \%)$ \\
PE-1 (peripheral) & $2 / 15(13 \%)$ & $4 / 29(14 \%)$ & $6 / 79(7.6 \%)$ & $12 / 123(9.8 \%)$ \\
PE-2 (subsegmental) & $7 / 15(46.6 \%)$ & $10 / 29(34.5 \%)$ & $24 / 79(30.4 \%)$ & $41 / 123(33.3 \%)$ \\
PE-3 (segmental) & $2 / 15(13.3 \%)$ & $5 / 29(17.2 \%)$ & $22 / 79(27.8 \%)$ & $29 / 123(23.6 \%)$ \\
PE-4 (central) & $4 / 15(26.6 \%)$ & $10 / 29(34.5 \%)$ & $27 / 79(34.2 \%)$ & $41 / 123(33.3 \%)$ \\
\hline Total & 35 & 88 & 200 & 323
\end{tabular}

PE, pulmonary embolism; CTPA, computed tomography pulmonary angiography.

Table 4. Characteristics of 123 patients with proven PE in CTPA according to age-groups

\begin{tabular}{|c|c|c|c|}
\hline \multicolumn{4}{|l|}{ Proven PE } \\
\hline Age, years & $<40$ & $40-60$ & $>60$ \\
\hline$n$ & 15 & 29 & 79 \\
\hline Sex (female/male) & $7 / 8$ & $9 / 20$ & $41 / 38$ \\
\hline Respiratory rate, /min & $20.4 \pm 4(14-20)$ & $20.2 \pm 6(14-36)$ & $19.0 \pm 4(14-30)$ \\
\hline Tachypnea (>20/min), $n(\%)$ & $7(46.6)$ & $8(27.5)$ & $21(26.6)$ \\
\hline Heart rate, /min & $94.6 \pm 19(62-138)$ & $89.7 \pm 14(63-139)$ & $94.9 \pm 14(72-126)$ \\
\hline Tachycardia (>100/min), $n(\%)$ & $6(40.0)$ & $8(28)$ & $24(30)$ \\
\hline \multicolumn{4}{|l|}{ Symptoms, $n(\%)$} \\
\hline Chest pain & $12(80)$ & $13(44.8)$ & $36(45.6)$ \\
\hline Dyspnea & $10(66.7)$ & $24(82.8)$ & $62(78.5)$ \\
\hline Cough & $6(40.0)$ & $4(13.8)$ & $20(25.3)$ \\
\hline Hemoptysis & $3(20)$ & $2(6.9)$ & $1(1.3)$ \\
\hline Pleuritic pain & $2(13.3)$ & $5(17.2)$ & $7(8.9)$ \\
\hline \multicolumn{4}{|l|}{ Further characteristics } \\
\hline Wells score & $3.4 \pm 2.4(0-8.0)$ & $3.1 \pm 3.3(0-10.0)$ & $3.6 \pm 2.8(0-10.0)$ \\
\hline Geneva score & $3.3 \pm 1.3(0-4.0)$ & $2.1 \pm 1.3(0-4.0)$ & $3.9 \pm 2.7(1.0-13.0)$ \\
\hline Leg pain/edema, $n(\%)$ & $5(33.3)$ & $8(27.6)$ & $41(51.9)$ \\
\hline Ultrasound of leg veins, $n(\%)$ & $10(66.6)$ & $14(48.3)$ & $41(51.9)$ \\
\hline Deep vein thrombosis, $n(\%)$ & $8(53.3)$ & $15(51.7)$ & $44(55.7)$ \\
\hline Right bundle branch block (ECG), $n(\%)$ & 0 & $1(3.4)$ & $2(2.5)$ \\
\hline S1Q3 (ECG), $n(\%)$ & $3(20)$ & $7(24.1)$ & $11(13.9)$ \\
\hline $\mathrm{D}$-dimers, $\mathrm{ng} / \mathrm{mL}$ & $1,603 \pm 1,601(30-3,230)$ & $4,851 \pm 2,357(1,430-7,770)$ & $4,762 \pm 2,349(1,200-9,840)$ \\
\hline Pathologic D-dimers, $n(\%)$ & $13 / 14(93)$ & $23 / 23(100.0)$ & $46 / 47(96)$ \\
\hline
\end{tabular}

ECG, electrocardiogram; PE, pulmonary embolism; CTPA, computed tomography pulmonary angiography.

calculation and documentation of the risk of PE (Wells score) seems to be mandatory in accordance with the corresponding guidelines [3-5]. In a similar retrospective analysis evaluating the role of CTPA in an emergency department in the USA, 295 patients in the year 2015 were analyzed [8]. The results showed a PE prevalence of 5.4\% in that study population. This result is similar to comparable studies from the USA in which positive PE rates of
$2 \%$ were shown $[9,16]$. Our results seem to be rather close to the rate of 30\% in European countries [17-22].

This divergence results from the fact that physicians in many European hospitals seem to adhere to guidelines more often than their American colleagues, generally being more restrictive in terms of ordering CTPA. CTPA is known to be more accessible to physicians in the USA [8]. Another explanation for the comparatively high rate of 
PE observed in our cohort might be the high proportion of peripheral and subsegmental extent of PE diagnosed in CTPA with both $>40 \%$ of all PE. Overdiagnosis of PE, including common diagnosis of peripheral and subsegmental PE, is reported in the literature due to an increase in imaging quality of CTPA [23, 24]. Care of subsegmental $\mathrm{PE}$ is still debatable. Surveillance of untreated subsegmental PE without deep vein thrombosis might be a therapeutic option $[25,26]$ In our study, all patients were symptomatic in a certain way, so anticoagulation therapy was undertaken also in subsegmental and peripheral PE (unless contraindicated) in our hospital. Proportion of peripheral and subsegmental PE was higher in younger ages of patients with PE.

PE was found in CTPA in $84 \%$ of our patients with high clinical risk (according to Wells score). 12\% of the patients with low risk had no determination of $\mathrm{D}$-dimers, probably due to underlying diseases such as chronic renal failure, cancer, or inflammation/infection that might interfere with the interpretation of pathologic levels of Ddimers. In contrast, in $68 \%$ of high-risk patients, the $\mathrm{D}$ dimer level was ascertained although guidelines do not recommend this approach. In daily practice, taking a blood sample is performed before or concurrently to anamnesis and physical examination to speed up the diagnostic process, especially when many patients had to be evaluated at the same time. In the intermediate-risk situation, a balanced diagnostic workup involving more clinical and laboratory parameters became more significant: $41 \%$ of our patients in this group had a PE. In the literature, the prevalence of $28-40.7 \%$ for the detection of $\mathrm{PE}$ in intermediate-risk patients is found [27]. Because $25 \%$ of our patients classified as low risk were still diagnosed with PE, the standard algorithm of ordering D-dimers and proceeding with CTPA in case of pathologic D-dimers should be followed to avoid the potentially fatal consequences of missed PE. Nevertheless, D-dimers were also regularly positive for patients without $\mathrm{PE}$ and showing diagnoses other than PE. This low specificity does not make isolated D-dimer testing without considering clinical parameters reliable enough.

Various risk factors listed in clinical scores seem to apply more often to the older population; however, PE as a probable diagnosis in younger patients should not be underestimated. In $43 \%$ of our patients $<40$ years, CTPA proved $\mathrm{PE}$. There are few data looking at the clinical presentation of young patients with PE. A retrospective analysis performed in the 1990s compared clinical presentation in $\mathrm{PE}$ of 40 younger patients with 40 older patients [28]. Clinical signs in younger patients were more subtle apart chest pain, whereas tachycardia and tachypnea were more common in the older group. In contrast, in our emergency department, patients $<40$ years were more symptomatic: tachycardia, tachypnea, cough, hemoptysis, and especially chest pain were found more often than in patients $\geq 40$ years. In a different study in 2015 , symptoms such as chest pain and hemoptysis were more common in the younger population [29].

It seems that in young patients presenting with any kind of these symptoms (or in combination) ordering CTPA should be prioritized or at least PE should be part of the differential diagnosis from the start. In general, PE as a differential diagnosis in young patients still seems to be undervalued because patients $<40$ years showed a relatively higher probability of $\mathrm{PE}$ than the other 2 patient age-groups of our analysis. Moreover, central PE was present in $27 \%$ of the 15 patients $<40$ years with PE. The extent of PE has been generally found to correlate with patient age [30].

More than half of patients (54.5\%) diagnosed with PE were found to have deep vein thrombosis (while only $1 \%$ of patients with an alternative diagnosis had 1). In 141 patients with PE in a South Korean study, the prevalence of deep vein thrombosis was $45.4 \%$ [31]. If thrombosis is to be expected in half of the patients with $\mathrm{PE}$, screening for deep vein thrombosis by performing compression ultrasound in Patients with confirmed PE in the emergency department seems advisable.

Certain weaknesses might impair the interpretation of our results because data were based on hospital records and retrospectively analyzed. The Wells score was mostly calculated retrospectively. Because the Wells score involves the parameter "an alternative diagnosis is less likely than PE," the physician would have calculated differently ad hoc, which might have classified the patient into a higher or lower risk category (considering the 3 points related to this factor). But even in the acute situation, this issue might be somewhat arbitrary. Another drawback is that only analysis of patients with CTPA was performed, so we cannot conclude for all patients (including those without CTPA), in particular for all young patients or all patients that would have had a low clinical risk and presented in the emergency department.

\section{Conclusion}

CTPA frequently helps to confirm PE in Patients with suspicion of PE in an emergency department of Internal Medicine. Even in low-risk calculations (Wells score) or
Al-Zaher/Vitali/Neurath/Goertz 
in young patients $<40$ years (with chest pain or dyspnea), the presence of $\mathrm{PE}$ is quite common. This should make us rethink PE in our diagnostic strategies by considering these aspects in future clinical scores and adapt them accordingly.

\section{Statement of Ethics}

This retrospective study complied with the ethics of the World Medical Association Declaration of Helsinki and was approved by the local Ethics Committee (No. 340_17Bc from august 20, 2018).

\section{Conflict of Interest Statement}

The authors have no conflicts of interest to declare.

\section{Funding Sources}

This research did not receive any specific funding from agencies in the public, commercial, or not-for-profit sectors.

\section{References}

1 Carvalho Bricola SA, Paiva EF, Lichtenstein A, Gianini RJ, Duarte JG, Shinjo SK, et al. Fatal pulmonary embolism in hospitalized patients: a large autopsy-based matched casecontrol study. Clinics. 2013;68(5):679-85.

2 Calder KK, Herbert M, Henderson SO. The mortality of untreated pulmonary embolism in emergency department patients. Ann Emerg Med. 2005;45(3):302-10.

3 Lim W, Le Gal G, Bates SM, Righini M, Haramati LB, Lang E, et al. American Society of Hematology 2018 guidelines for management of venous thromboembolism: diagnosis of venous thromboembolism. Blood Adv. 2018; 2(22):3226-56.

4 Saar JA, Maack C. [Diagnosis and management of acute pulmonary embolism. ESC guidelines 2014]. Herz. 2015;40(8):1048-54.

5 Konstantinides SV, Meyer G, Becattini C, Bueno H, Geersing GJ, Harjola VP, et al. 2019 ESC Guidelines for the diagnosis and management of acute pulmonary embolism developed in collaboration with the European Respiratory Society (ERS): the task force for the diagnosis and management of acute pulmonary embolism of the European Society of Cardiology (ESC). Eur Respir J. 2019;54(3).

6 Hendriksen JM, Geersing GJ, Lucassen WA, Erkens PM, Stoffers HE, van Weert HC, et al. Diagnostic prediction models for suspected pulmonary embolism: systematic review and independent external validation in primary care. BMJ. 2015;351:h4438.

7 Theunissen J, Scholing C, van Hasselt WE, van der Maten J, Ter Avest E. A retrospective analysis of the combined use of PERC rule and wells score to exclude pulmonary embolism in the emergency department. Emerg Med J. 2016;33(10):696-701.

8 Osman M, Subedi SK, Ahmed A, Khan J, Dawood T, Ríos-Bedoya CF, et al. Computed tomography pulmonary angiography is overused to diagnose pulmonary embolism in the emergency department of academic community hospital. J Community Hosp Intern Med Perspect. 2018;8(1):6-10.
9 Perelas A, Dimou A, Saenz A, Rhee JH, Teerapuncharoen K, Rowden A, et al. CT pulmonary angiography utilization in the emergency department: diagnostic yield and adherence to current guidelines. Am J Med Qual. 2015;30(6):571-7.

10 Righini M, Van Es J, Den Exter PL, Roy PM, Verschuren F, Ghuysen A, et al. Age-adjusted D-dimer cutoff levels to rule out pulmonary embolism: the ADJUST-PE study. JAMA. 2014;311(11):1117-24.

11 Schouten HJ, Geersing GJ, Koek HL, Zuithoff NP, Janssen KJ, Douma RA, et al. Diagnostic accuracy of conventional or age adjusted Ddimer cut-off values in older patients with suspected venous thromboembolism: systematic review and meta-analysis. BMJ. 2013; 346:f2492.

12 Wells PS, Ginsberg JS, Anderson DR, Kearon C, Gent M, Turpie AG, et al. Use of a clinical model for safe management of patients with suspected pulmonary embolism. Ann Intern Med. 1998;129(12):997-1005.

13 Wells PS, Hirsh J, Anderson DR, Lensing AW, Foster G, Kearon C, et al. Accuracy of clinical assessment of deep-vein thrombosis. Lancet. 1995;345(8961):1326-30.

14 Le Gal G, Righini M, Roy PM, Sanchez O, Aujesky D, Bounameaux H, et al. Prediction of pulmonary embolism in the emergency department: the revised geneva score. Ann Intern Med. 2006;144(3):165-71.

15 Alonso Martinez JL, Anniccherico Sánchez FJ, Urbieta Echezarreta MA, García IV, Álvaro JR. Central versus peripheral pulmonary embolism: analysis of the impact on the physiological parameters and long-term survival. N Am J Med Sci. 2016;8(3):134-42.

16 Adams DM, Stevens SM, Woller SC, Evans RS, Lloyd JF, Snow GL, et al. Adherence to PIOPED II investigators' recommendations for computed tomography pulmonary angiography. Am J Med. 2013;126(1):36-42.
17 Costantino MM, Randall G, Gosselin M, Brandt M, Spinning K, Vegas CD. CT angiography in the evaluation of acute pulmonary embolus. AJR Am J Roentgenol. 2008;191(2): 471-4.

18 Courtney DM, Kline JA, Kabrhel C, Moore CL, Smithline HA, Nordenholz KE, et al. Clinical features from the history and physical examination that predict the presence or absence of pulmonary embolism in symptomatic emergency department patients: results of a prospective, multicenter study. Ann Emerg Med. 2010;55(4):307-e1.

19 Douma RA, le Gal G, Söhne M, Righini M, Kamphuisen PW, Perrier A, et al. Potential of an age adjusted D-dimer cut-off value to improve the exclusion of pulmonary embolism in older patients: a retrospective analysis of three large cohorts. BMJ. 2010;340:c1475.

20 Penaloza A, Verschuren F, Meyer G, Quentin-Georget S, Soulie C, Thys F, et al. Comparison of the unstructured clinician gestalt, the wells score, and the revised geneva score to estimate pretest probability for suspected pulmonary embolism. Ann Emerg Med. 2013;62(2):117-e2

21 van der Hulle T, Cheung WY, Kooij S, Beenen LFM, van Bemmel T, van Es J, et al. Simplified diagnostic management of suspected pulmonary embolism (the YEARS study): a prospective, multicentre, cohort study. Lancet. 2017; 390(10091):289-97.

22 Righini M, Le Gal G, Aujesky D, Roy PM, Sanchez O, Verschuren F, et al. Diagnosis of pulmonary embolism by multidetector $\mathrm{CT}$ alone or combined with venous ultrasonography of the leg: a randomised non-inferiority trial. Lancet. 2008;371(9621):1343-52.

23 Hutchinson BD, Navin P, Marom EM, Truong MT, Bruzzi JF. Overdiagnosis of pulmonary embolism by pulmonary CT angiography. AJR Am J Roentgenol. 2015;205(2):2717.

24 Wiener RS, Schwartz LM, Woloshin S. Time trends in pulmonary embolism in the United States: evidence of overdiagnosis. Arch Intern Med. 2011;171(9):831-7. 
25 Bariteau A, Stewart LK, Emmett TW, Kline JA. Systematic review and meta-analysis of outcomes of patients with subsegmental pulmonary embolism with and without anticoagulation treatment. Acad Emerg Med. 2018; 25(7):828-35.

26 Kearon C, Akl EA, Ornelas J, Blaivas A, Jimenez D, Bounameaux H, et al. Antithrombotic therapy for VTE disease: CHEST guideline and expert panel report. Chest. 2016; 149(2):315-52.
27 Miniati M, Pistolesi M, Marini C, Di Ricco G, Formichi B, Prediletto R, et al. Value of perfusion lung scan in the diagnosis of pulmonary embolism: results of the prospective investigative study of acute Pulmonary Embolism Diagnosis (PISA-PED). Am J Respir Crit Care Med. 1996;154(5):1387-93.

28 Green RM, Meyer TJ, Dunn M, Glassroth J. Pulmonary embolism in younger adults. Chest. 1992;101(6):1507-11.

29 Zaibi H, Maazaoui S, Amar JB, Dhahri B, Ali Baccar M, Azzebi S, et al. Pulmonary embolism in young adults, what particularities? Eur Respir J. 2015;46:PA2486. http://dx.doi. org/10.1183/13993003.congress-2015. PA2486.
30 Garcia-Sanz MT, Pena-Alvarez C, LopezLandeiro P, Bermo-Dominguez A, Fonturbel T, Gonzalez-Barcala FJ. Symptoms, location and prognosis of pulmonary embolism. Rev Port Pneumol. 2014;20:194-9. http://dx.doi. org/10.1016/j.rppneu.2013.09.006.

31 Lee JS, Moon T, Kim TH, Kim SY, Choi JY, Lee KB, et al. Deep vein thrombosis in patients with pulmonary embolism: prevalance, clinical significance and outcome. Vasc Specialist Int. 2016;32(4):166-74. 